\title{
Improvement in 24-hour bronchodilation and symptom control with aclidinium bromide versus tiotropium and placebo in symptomatic patients with COPD: post hoc analysis of a Phase Illb study
}

\author{
This article was published in the following Dove Press journal: \\ International Journal of COPD \\ 14 June 2017 \\ Number of times this article has been viewed
}

Jutta Beier'

Robert $\mathrm{Mroz}^{2,3}$

Anne-Marie Kirsten ${ }^{4}$

Ferran Chuecos ${ }^{5}$

Esther Garcia Gil ${ }^{5}$

'insaf Respiratory Research Institute, Wiesbaden, Germany; ${ }^{2}$ Centrum Medycyny Oddechowej, ${ }^{3}$ Medical University of Białystok, Białystok, Poland; ${ }^{4}$ Pulmonary Research Institute at LungenClinic Grosshansdorf, Airway Research Center North, German Center for Lung Research, Grosshansdorf, Germany;

${ }^{5}$ AstraZeneca PLC, Barcelona, Spain
Background: A previous Phase IIIb study (NCT01462929) in patients with moderate to severe COPD demonstrated that 6 weeks of treatment with aclidinium led to improvements in 24-hour bronchodilation comparable to those with tiotropium, and improvement of symptoms versus placebo. This post hoc analysis was performed to assess the effect of treatment in the symptomatic patient group participating in the study.

Methods: Symptomatic patients (defined as those with Evaluating Respiratory Symptoms [E-RS $\left.{ }^{T M}\right]$ in COPD baseline score $\geq 10$ units) received aclidinium bromide $400 \mu \mathrm{g}$ twice daily (BID), tiotropium $18 \mu \mathrm{g}$ once daily (QD), or placebo, for 6 weeks. Lung function, COPD respiratory symptoms, and incidence of adverse events (AEs) were assessed.

Results: In all, 277 symptomatic patients were included in this post hoc analysis. Aclidinium and tiotropium treatment improved forced expiratory volume in 1 second $\left(\mathrm{FEV}_{1}\right)$ from baseline to week 6 at all time points over 24 hours versus placebo. In addition, improvements in FEV, from baseline during the nighttime period were observed for aclidinium versus tiotropium on day 1 (aclidinium $157 \mathrm{~mL}$, tiotropium $67 \mathrm{~mL} ; P<0.001$ ) and week 6 (aclidinium $153 \mathrm{~mL}$, tiotropium $90 \mathrm{~mL} ; P<0.05)$. Aclidinium improved trough $\mathrm{FEV}_{1}$ from baseline versus placebo and tiotropium at day 1 (aclidinium $136 \mathrm{~mL}$, tiotropium $68 \mathrm{~mL} ; P<0.05$ ) and week 6 (aclidinium $137 \mathrm{~mL}$, tiotropium $71 \mathrm{~mL} ; P<0.05$ ). Aclidinium also improved early-morning and nighttime symptom severity, limitation of early-morning activities, and E-RS Total and domain scores versus tiotropium (except E-RS Chest Symptoms) and placebo over 6 weeks. Tolerability showed similar incidence of AEs in each arm.

Conclusion: In this post hoc analysis of symptomatic patients with moderate to severe COPD, aclidinium $400 \mu \mathrm{g}$ BID provided additional improvements compared with tiotropium $18 \mu \mathrm{g}$ QD in: 1) bronchodilation, particularly during the nighttime, 2) daily COPD symptoms (E-RS), 3) early-morning and nighttime symptoms, and 4) early-morning limitation of activity.

Keywords: COPD, 24-hour bronchodilation, long-acting muscarinic antagonist, nighttime, symptoms

\section{Introduction}

Symptoms of COPD can vary in severity over a 24-hour period, and studies indicate that they are generally worse in the early morning and at nighttime. ${ }^{1-3}$ Symptoms include chronic cough, sputum production, and breathlessness, which can severely impact on a patient's daily activities and overall well-being, ${ }^{3}$ and have a corresponding high socioeconomic burden. ${ }^{4}$ Estimates suggest that the frequency of nocturnal symptoms insaf Respiratory Research Institute,

Biebricher Allee 34, 65I87,

Wiesbaden, Germany

Tel +496119854410

Fax +496II 9854348

Email j.beier@insaf-wi.de 
and symptomatic sleep disturbance may exceed $75 \%$ in patients with COPD, and potential long-term consequences may include lung function changes, increased exacerbation frequency, emergence or worsening of cardiovascular disease, impaired quality of life, and increased mortality. ${ }^{1}$ It is therefore important that symptoms over the entire 24-hour day are identified and managed appropriately.

In order to provide appropriate therapy, clinical guidelines (Global initiative for chronic Obstructive Lung Disease [GOLD]) suggest that symptoms, airflow limitation, and risk of exacerbations are assessed. ${ }^{5}$ Patients are classified into one of four groups according to their symptom burden and risk of exacerbations: A, low risk, less symptoms; B, low risk, more symptoms; C, high risk, less symptoms; or D, high risk, more symptoms, ${ }^{5}$ current evidence suggests that bronchodilator treatment may be more effective in those patients who are considered symptomatic (ie, groups B and D). ${ }^{5}$

Bronchodilator therapies are a mainstay of COPD treatment, with two classes of long-acting bronchodilators currently available: long-acting muscarinic antagonists (LAMAs) and long-acting $\beta_{2}$-agonists (LABAs). LAMAs inhibit the action of acetylcholine at muscarinic receptors, while LABAs enhance cAMP signaling through stimulation of $\beta_{2}$-adrenergic receptors, resulting in the relaxation of bronchial smooth muscle. ${ }^{5}$ The LAMA aclidinium bromide is a maintenance bronchodilator therapy for adults with COPD.

The efficacy and tolerability results from a Phase IIIb study in patients with moderate to severe COPD, who received either aclidinium $400 \mu \mathrm{g}$ twice daily (BID), the active comparator tiotropium $18 \mu \mathrm{g}$ once daily (QD), or placebo have been previously reported. ${ }^{6}$ Briefly, following 6 weeks of treatment, patients receiving aclidinium $400 \mu \mathrm{g}$ BID demonstrated improvements in 24-hour bronchodilation, compared with placebo, that were comparable with tiotropium $18 \mu \mathrm{g}$ QD. In addition, COPD symptoms significantly improved from baseline with aclidinium, but not tiotropium, compared with placebo. ${ }^{6}$ These results were similar to those observed in a prior 2-week Phase IIa trial. ${ }^{7}$ Furthermore, a recent real-world study in patients with COPD reported improvements in nighttime and early-morning symptoms, limitation of morning activities, and quality of life over 3 months with aclidinium $400 \mu \mathrm{g}$ BID, compared with baseline. ${ }^{8}$ Since aclidinium has a greater impact on COPD symptoms than tiotropium, ${ }^{9,10}$ and the "more symptomatic" patient groups stand to benefit more from bronchodilator treatment than the "less symptomatic" groups, aclidinium may provide an additional therapeutic benefit over tiotropium in these patients.

This study reports the findings of a post hoc analysis, which focused on the response in the symptomatic patient group. The key objective of this analysis was to identify any differences in 24-hour lung function and symptom control between treatment with aclidinium $400 \mu \mathrm{g}$ BID and tiotropium $18 \mu \mathrm{g}$ QD in this population of patients.

\section{Methods}

\section{Study design and patients Overall study}

This was a randomized, double-blind, double-dummy, placebo- and active comparator-controlled, multicenter Phase IIIb study in patients with moderate to severe COPD (ClinicalTrials.gov identifier: NCT01462929). Full details of the study design and inclusion/exclusion criteria have been published previously. ${ }^{6}$ Briefly, patients with COPD aged $\geq 40$ years with a smoking history (current or previous) of $\geq 10$ packyears were eligible to enter the study. Patients with moderate to severe COPD (for whom long-acting bronchodilators are recommended $)^{5}$ had post-salbutamol forced expiratory volume in 1 second $\left(\mathrm{FEV}_{1}\right) \geq 30 \%$ and $<80 \%$ of the predicted normal value, $\mathrm{FEV}_{1} /$ forced vital capacity $<70 \%$. Use of long-acting bronchodilators other than the investigative treatment was not permitted. Use of salbutamol pressurized metered dose inhaler (100 $\mu \mathrm{g} /$ puff) was permitted as relief medication as needed (except $\leq 6$ hours before each visit). Patients were permitted to continue use of oral sustained-release theophylline (use of other methylxanthines was not permitted), inhaled corticosteroids, and oral or parenteral corticosteroids (equivalent to $\leq 10 \mathrm{mg}$ /day or $20 \mathrm{mg}$ every other day of prednisone) if treatment was stable $\geq 4$ weeks prior to screening, except $\leq 6$ hours before each visit. Oxygen therapy (except $\leq 2$ hours before each visit) was permitted. After a screening visit, patients underwent a 2- to 3 -week run-in period to assess disease stability. Eligible patients were randomized (2:2:1) to receive aclidinium bromide $400 \mu \mathrm{g}$ BID in the morning and evening via the Genuair ${ }^{\mathrm{TM}} /$ Pressair $^{\circledR}$ (registered trademark of AstraZeneca group of companies; for use within the USA as Pressair ${ }^{\circledR}$ and as Genuair ${ }^{\mathrm{TM}}$ within all other licensed territories) multidose dry powder inhaler, tiotropium $18 \mu \mathrm{g}$ QD in the morning via the HandiHaler ${ }^{\circledR}$, or placebo for 6 weeks.

The study was approved by an independent ethics committee at each site (Table S1) and was conducted in accordance with the Declaration of Helsinki, the International Conference on Harmonisation, and Good Clinical Practice guidelines. All patients provided written informed consent. 


\section{Post hoc analysis}

This post hoc analysis assessed symptomatic patients, defined as those patients with an Evaluating Respiratory Symptoms in COPD (E-RS:COPD ${ }^{\mathrm{TM}}$ [The EXACT ${ }^{\mathrm{TM}}$ and E-RS ${ }^{\mathrm{TM}}$ are owned by Evidera. Permission to use these instruments may be obtained from Evidera \{exactpro@evidera.com $\}$ ]; formerly known as EXAcerbations of Chronic pulmonary disease Tool [EXACT]-RS) baseline score $\geq 10$ units. This threshold was chosen based on data indicating that an E-RS score $\geq 10$ units differentiated between asymptomatic (GOLD groups A and $\mathrm{C}$ ) and symptomatic (GOLD groups B and D) patients. ${ }^{11}$

\section{Assessments and endpoints}

\section{Lung function}

Lung function was assessed over 24 hours post-dose on day 1 and at week 6 . The primary endpoint was change from baseline in normalized $\mathrm{FEV}_{1}$ area under the curve (AUC) over 24 hours post-morning dose $\left(\mathrm{AUC}_{0-24 / 24 \mathrm{~h}}\right)$ at week 6 . The secondary endpoint was change from baseline in normalized $\mathrm{FEV}_{1}$ AUC over the nighttime period $\left(\mathrm{AUC}_{12-24 / 12 \mathrm{~h}}\right)$ at week 6 . An additional lung function endpoint was change from baseline in morning pre-dose (trough) $\mathrm{FEV}_{1}$.

\section{COPD symptoms}

Every evening, patients completed the 14-item EXACT (recall period of "today") via electronic diaries and daily COPD symptoms scores were derived using E-RS scoring algorithms. The E-RS uses the 11 respiratory symptom items from the 14-item EXACT and assesses both overall daily respiratory COPD symptoms (RS-Total score; score range, $0-40$, with higher scores indicating more severe symptoms) and specific respiratory symptoms using three subscales (RS-Breathlessness [score range, 0-17], RS-Cough and Sputum [score range, 0-11], and RS-Chest Symptoms [the sum of three items related to chest congestion/discomfort; score range, $0-12]) \cdot{ }^{12,13}$ E-RS Total and domain scores were assessed at baseline and over the 6-week study duration. Patients who achieved a clinically meaningful improvement from baseline (E-RS Total score $\geq-2$ units) were considered to be responders; this responder definition was proposed based on results from three randomized controlled trials. ${ }^{14}$ Responder status was assessed over the 6 weeks of the study.

To assess the severity of early-morning and nighttime symptoms, an additional COPD symptoms questionnaire developed by the study sponsor was completed by patients each morning via electronic diaries (5-point scale: $1=$ "did not experience symptoms"; $5=$ "very severe") and included individual morning symptoms of cough, wheeze, shortness of breath, and phlegm (5-point scale: $0=$ "no symptoms"; $4=$ "very severe symptoms"), as well as limitation of morning activities (5-point scale: $1=$ "not at all"; $5=$ "a very great deal"). Since this study, these questionnaires have been developed and evaluated further. ${ }^{15,16}$

\section{Safety and tolerability}

Treatment-emergent adverse events (TEAEs) were recorded throughout the study.

\section{Statistical analyses}

Efficacy data are reported for the intent-to-treat population, defined as all randomized patients who received at least one dose of study medication and who had at least one baseline and post-baseline $\mathrm{FEV}_{1}$ value. Endpoints were assessed using an analysis of covariance model with treatment and sex as factors, and age and baseline values as covariates. Between-group least squares mean differences and $95 \%$ confidence intervals were calculated for all treatment group comparisons.

\section{Results \\ Patients}

In all, 414 patients were randomized to treatment in the overall study (2:2:1 ratio), of which 277 were defined as symptomatic (E-RS baseline score $\geq 10$ units) and included in this post hoc subgroup analysis (placebo: $n=60$; aclidinium $400 \mu \mathrm{g}: \mathrm{n}=116$; tiotropium $18 \mu \mathrm{g}: \mathrm{n}=101$ ) (Figure 1). The percentages of patients in each treatment arm of this post hoc analysis were similar to those in the primary study (placebo, $21.7 \%$ vs $20.5 \%$; aclidinium $400 \mu \mathrm{g}, 41.9 \%$ vs $41.3 \%$; tiotropium $18 \mu \mathrm{g}, 36.5 \%$ vs $38.2 \%$, respectively).

Demographics and baseline characteristics in the subgroup of symptomatic patients were similar to those in the overall study population (symptomatic patients: mean age 62.1 years, $65.0 \%$ male, $54.5 \%$ current smokers, postbronchodilator $\mathrm{FEV}_{1} 54.6 \%$ predicted). Patient demographics and baseline characteristics for symptomatic patients were also similar across treatment arms, with the exception of a higher proportion of male patients in the active treatment groups compared with placebo, and a higher proportion of patients with severe COPD in the tiotropium group (Table 1). Mean post-bronchodilator percent predicted $\mathrm{FEV}_{1}$ and $\mathrm{COPD}$ symptoms scores at baseline were similar across treatment arms (Table 1).

\section{Efficacy \\ Lung function}

Lung function endpoints in the subgroup of symptomatic patients were similar to those in the overall population. 


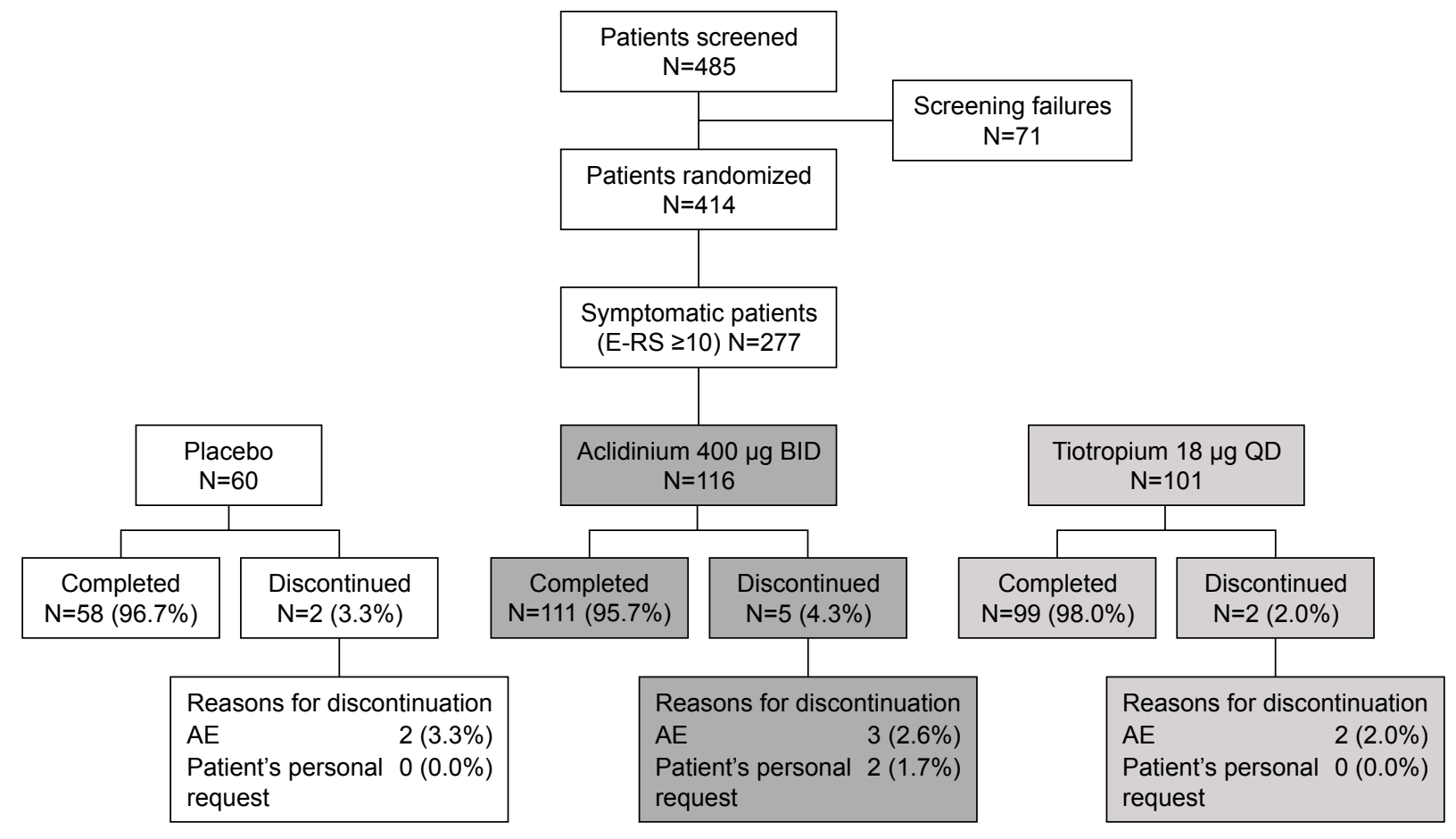

Figure I Patient flow diagram.

Abbreviations: AE, adverse event; BID, twice daily; E-RS, Evaluating Respiratory Symptoms; QD, once daily.

Aclidinium $400 \mu \mathrm{g}$ BID and tiotropium $18 \mu \mathrm{g}$ QD both improved $\mathrm{FEV}_{1}$ over 24 hours $\left(\mathrm{AUC}_{0-24 / 24 \mathrm{~h}}\right.$ ) from baseline at week 6 compared with placebo (aclidinium, $140 \mathrm{~mL}$; tiotropium, $106 \mathrm{~mL}$; both $P<0.01$ ). Furthermore, treatment with aclidinium $400 \mu \mathrm{g}$ BID and tiotropium $18 \mu \mathrm{g}$ QD improved $\mathrm{FEV}_{1}$ from baseline at week 6 at all time points over 24 hours, compared with placebo (Figure 2). During the nighttime period $\left(\mathrm{AUC}_{12-24 \mathrm{~h} / 12 \mathrm{~h}}\right)$, improvements from baseline compared with placebo were greater with aclidinium $400 \mu \mathrm{g}$ BID than tiotropium $18 \mu \mathrm{g}$ QD on day 1 (157 vs $67 \mathrm{~mL}$ for aclidinium and tiotropium, respectively; $P<0.001$ ) and week 6 (153 vs $90 \mathrm{~mL}$ for aclidinium and tiotropium, respectively; $P<0.05)$.

Aclidinium $400 \mu \mathrm{g}$ BID also demonstrated improvements in trough $\mathrm{FEV}_{1}$ from baseline versus placebo and tiotropium at day 1 (136 vs $68 \mathrm{~mL}$ for aclidinium and tiotropium, respectively; $P<0.05)$ and week $6(137 \mathrm{vs} 71 \mathrm{~mL}$ for aclidinium and tiotropium, respectively; $P<0.05)$ in symptomatic patients (Figure 3).

\section{COPD symptoms in symptomatic patients}

In this subgroup of symptomatic patients, the improvement from baseline in E-RS Total score was greater with aclidinium compared with placebo $(P<0.001)$ and tiotropium $(P<0.05)$ over 6 weeks (Figure $4 \mathrm{~A})$ : -2.8 units with aclidinium versus -0.7 units with placebo and -1.6 units with tiotropium. For each of the E-RS domains, greater improvements from baseline in E-RS score in symptomatic patients were also observed for aclidinium over 6 weeks of treatment (RS-Breathlessness and RS-Cough and Sputum: $P<0.05$ vs tiotropium and $P<0.01$ vs placebo; RS-Chest Symptoms: $P<0.05$ vs placebo) (Figure 4A). A higher percentage of patients in the aclidinium $400 \mu \mathrm{g}$ treatment arm were E-RS responders (52.6\%) compared with placebo $(28.3 \% ; P<0.01)$ and tiotropium $18 \mu \mathrm{g}(37.6 \% ; P<0.05)$ (Figure 4B) over 6 weeks.

Overall early-morning symptom severity was reduced in the subgroup of symptomatic patients over 6 weeks with aclidinium treatment versus placebo $(P<0.01)$ and tiotropium $(P<0.05$; Figure $5 \mathrm{~A})$. Aclidinium also demonstrated improvements in individual early-morning symptom domains; shortness of breath and cough symptom scores improved in symptomatic patients treated with aclidinium compared with placebo over 6 weeks (both $P<0.05$; Figure 5A). A reduction in overall nighttime symptom severity from baseline was observed over 6 weeks with aclidinium versus placebo and tiotropium in symptomatic patients (both $P<0.05$; Figure 5B). Numerical improvements in early-morning or nighttime symptom severity were observed for tiotropium versus placebo in this subgroup. 
Table I Patient demographics in symptomatic patients (E-RS baseline score $\geq 10$ units)

\begin{tabular}{|c|c|c|c|}
\hline & $\begin{array}{l}\text { Placebo } \\
(\mathrm{N}=60)\end{array}$ & $\begin{array}{l}\text { Aclidinium } \\
400 \mu \mathrm{g} \text { BID } \\
(\mathrm{N}=\mathrm{I} \mid \mathrm{6})\end{array}$ & $\begin{array}{l}\text { Tiotropium } \\
\text { I8 } 4 \text { g QD } \\
(\mathrm{N}=101)\end{array}$ \\
\hline Gender (male), n (\%) & $35(58.3)$ & $75(64.7)$ & $70(69.3)$ \\
\hline Age (years), mean (SD) & $62.1(8.2)$ & $61.4(8.4)$ & $62.9(8.1)$ \\
\hline \multicolumn{4}{|l|}{ Race, n (\%) } \\
\hline White & $59(98.3)$ & $116(100)$ & $101(100)$ \\
\hline BMI $\left(\mathrm{kg} / \mathrm{m}^{2}\right)$, mean $(\mathrm{SD})$ & $26.8(5.4)$ & $27.4(4.9)$ & $27.1(4.8)$ \\
\hline Current smoker, n (\%) & 31 (5I.7) & $64(55.2)$ & $56(55.5)$ \\
\hline Smoking consumption (pack-years), mean (SD) & $38.8(14.3)$ & $41.7(23.7)$ & $42.4(17.1)$ \\
\hline COPD duration (years), mean (SD) & $9.63(6.7)$ & $8.44(5.8)$ & $8.44(6.6)$ \\
\hline \multicolumn{4}{|l|}{ Post-bronchodilator FEV (L) } \\
\hline Mean (SD) & $1.56(0.54)$ & $1.59(0.50)$ & $1.53(0.49)$ \\
\hline \% predicted, mean (SD) & $55.2(12.1)$ & $55.5(13.4)$ & $53.0(13.1)$ \\
\hline Mean bronchial reversibility, \% (SD) & $10.1(9.7)$ & $14.7(15.2)$ & $10.8(12.8)$ \\
\hline \multicolumn{4}{|l|}{ COPD severity, ${ }^{\mathrm{a}} \mathrm{n}(\%)$} \\
\hline Moderate & $40(66.7)$ & $72(62.1)$ & $56(56.0)$ \\
\hline Severe & $20(33.3)$ & $44(37.9)$ & $44(44.0)$ \\
\hline \multicolumn{4}{|l|}{ Exacerbations in previous year, $\mathrm{n}(\%)$} \\
\hline 0 & $46(76.7)$ & $75(64.7)$ & $67(66.3)$ \\
\hline 1 & $12(20.0)$ & $31(26.7)$ & $30(29.7)$ \\
\hline$\geq 2$ & $2(3.3)$ & $10(8.6)$ & $4(4.0)$ \\
\hline E-RS Total score (SD) & $16.2(4.3)$ & $16.4(4.2)$ & $15.8(3.8)$ \\
\hline E-RS Cough and Sputum (SD) & $4.3(1.6)$ & $4.5(1.4)$ & $4.4(1.1)$ \\
\hline E-RS Chest Symptoms (SD) & $3.9(1.3)$ & $4.0(1.4)$ & $3.7(1.3)$ \\
\hline E-RS Breathlessness (SD) & $8.0(2.5)$ & $7.9(2.5)$ & $7.7(2.5)$ \\
\hline \multicolumn{4}{|l|}{ Severity of early-morning symptoms } \\
\hline Any (SD) & $2.5(0.5)$ & $2.6(0.5)$ & $2.5(0.5)$ \\
\hline Cough (SD) & $1.4(0.8)$ & $1.5(0.7)$ & $1.4(0.7)$ \\
\hline Wheeze (SD) & $0.9(0.9)$ & $0.9(0.8)$ & $0.8(0.7)$ \\
\hline Shortness of breath (SD) & $\mathrm{I} .3(0.7)$ & $1.3(0.8)$ & I.I (0.8) \\
\hline Phlegm (SD) & $0.8(0.9)$ & I.I (0.9) & $0.9(0.9)$ \\
\hline Limitation of activity (SD) & $2.3(0.6)$ & $2.3(0.6)$ & $2.3(0.7)$ \\
\hline Severity of nighttime symptoms (SD) & $2.1(0.7)$ & $2.2(0.6)$ & $2.1(0.6)$ \\
\hline
\end{tabular}

Notes: ${ }^{a} \mathrm{GOLD}$ stage II (moderate): $\mathrm{FEV} / \mathrm{FVC}<0.70$, and post-bronchodilator $\mathrm{FEV}_{1} \geq 50 \%$ and $<80 \%$ predicted; GOLD stage III (severe): $\mathrm{FEV} / \mathrm{FVC}<0.70$, and post-bronchodilator $\mathrm{FEV}, \geq 30 \%$ and $<50 \%$ predicted.

Abbreviations: BID, twice daily; BMl, body mass index; E-RS, Evaluating Respiratory Symptoms; FEV GOLD, Global initiative for chronic Obstructive Lung Disease; QD, once daily; SD, standard deviation.

In symptomatic patients, limitation of early-morning activity caused by COPD symptoms was reduced from baseline over 6 weeks with aclidinium versus placebo $(P<0.01)$ and tiotropium $(P<0.05)$, but not with tiotropium versus placebo (Figure 5C).

\section{Safety and tolerability}

In the subgroup of symptomatic patients, the incidence of TEAEs was comparable in the placebo (26.7\%), aclidinium (28.4\%), and tiotropium (32.7\%) groups. Similar to the overall study population, the most commonly reported TEAEs in symptomatic patients were headache (5.8\%) and nasopharyngitis $(5.1 \%)$. Other common TEAEs ( $\geq 2 \%$ of patients overall) were COPD exacerbation (2.5\%), back pain $(2.5 \%)$, and cough $(2.2 \%)$. The majority of TEAEs were mild or moderate in intensity. There were few serious TEAEs (1.4\% overall) and no deaths in the subgroup of symptomatic patients. In total, five patients $(1.8 \%)$ discontinued due to TEAEs and one patient $(0.4 \%)$ discontinued due to a serious TEAE, with COPD exacerbation being the most common cause (1.4\%).

\section{Discussion}

Assessment of treatment efficacy in symptomatic patients has clinical significance, as treatment guidelines recommend that such patients are treated in order to improve lung function and reduce symptoms. ${ }^{17}$ This post hoc analysis was performed to evaluate the 24-hour effect of treatment with aclidinium bromide $400 \mu \mathrm{g}$ BID, tiotropium $18 \mu \mathrm{g}$ QD, or placebo, in 277 symptomatic patients with moderate to severe 


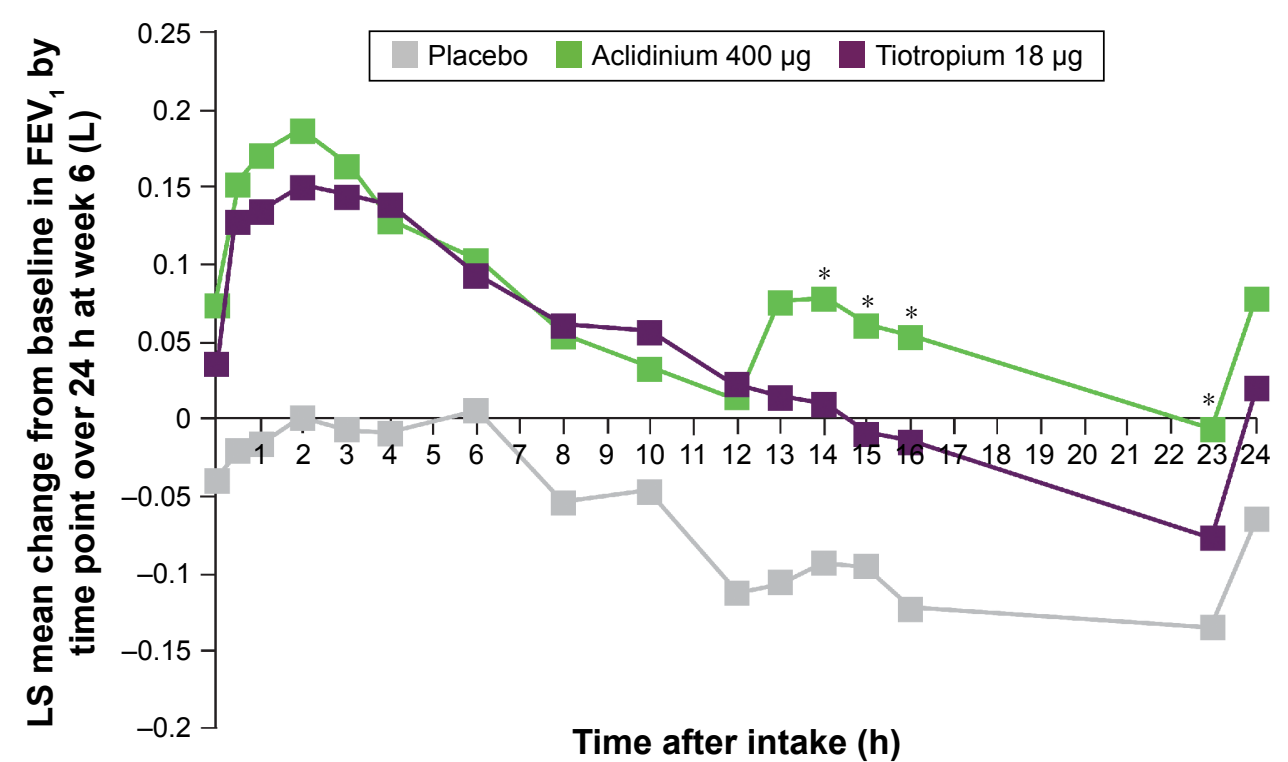

Figure 2 Symptomatic patients: mean changes from baseline in FEV, at week 6 over 24 hours.

Notes: Placebo $\mathrm{N}=60$, aclidinium $400 \mu \mathrm{g} \mathrm{N}=1$ I 6 , tiotropium $18 \mu \mathrm{g} \mathrm{N}=10 \mathrm{I}$. $* P<0.05$ versus tiotropium; $P<0.05$ for aclidinium $400 \mu \mathrm{g}$ versus placebo and tiotropium $18 \mu \mathrm{g}$ versus placebo at all time points, except aclidinium at 10 hours $(P=0.08)$ and tiotropium at 23 hours $(P=0.14)$.

Abbreviations: $\mathrm{FEV}_{1}$, forced expiratory volume in I second; LS, least squares.

COPD participating in a Phase III study. This subgroup of symptomatic patients constituted a substantial proportion of the overall patients $(277 / 414 ; 45 \%)$.

In the subgroup of symptomatic patients, 6 weeks of treatment with aclidinium BID showed improvements from baseline in $\mathrm{FEV}_{1}$ at all time points over 24 hours (compared with placebo), and $\mathrm{FEV}_{1}$ was higher than tiotropium QD at most 12- to 24-hour time points. Aclidinium treatment also led to greater improvements in trough $\mathrm{FEV}_{1}$ compared with tiotropium. Furthermore, during the nighttime period at both day 1 and week 6, improvements from baseline in $\mathrm{FEV}_{1}$ (compared with placebo) were greater with aclidinium than with tiotropium.

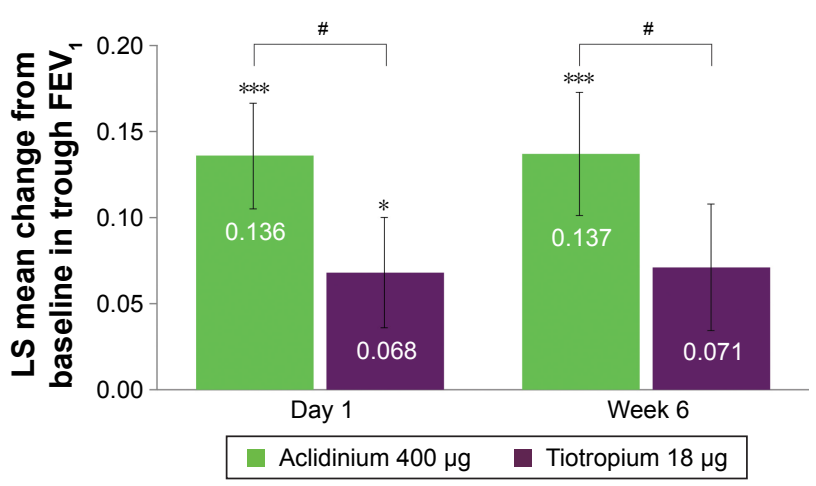

Figure 3 Symptomatic patients: change from baseline in trough $\mathrm{FEV}$, versus placebo at day I and week 6 .

Notes: Placebo $\mathrm{N}=60$, aclidinium $400 \mu \mathrm{g} \mathrm{N}=1$ | 6, tiotropium $18 \mu \mathrm{g} \mathrm{N}=101 . * P<0.05$, $* * * P<0.00$ I versus placebo; ${ }^{*} P<0.05$ versus tiotropium.

Abbreviations: $\mathrm{FEV}_{1}$, forced expiratory volume in I second; LS, least squares.
Patient symptoms also improved following treatment. After 6 weeks, the improvement in E-RS score was greater with aclidinium compared with both placebo and tiotropium, as indicated by changes in RS-Breathlessness, RS-Cough and Sputum, and E-RS Total scores. In addition, the percentage of patients defined as E-RS responders increased with aclidinium compared with tiotropium or placebo. Improvement over placebo and tiotropium was also observed in early-morning symptom severity, nighttime symptom severity, individual early-morning symptoms (shortness of breath and cough), and limitation of early-morning activity caused by symptoms. Safety and tolerability in symptomatic patients appeared to be similar to that in the overall study population, with the most commonly reported TEAEs being headache and nasopharyngitis.

The overall study population included both symptomatic and asymptomatic patients. Results have been previously reported and indicated that aclidinium provided significant 24-hour bronchodilation versus placebo from day 1 , with comparable efficacy to tiotropium after 6 weeks. ${ }^{6}$ In this post hoc analysis, some notable differences were observed in the symptomatic patient group. Improvements in bronchodilation during the nighttime period were greater with aclidinium than with tiotropium in symptomatic patients, whereas in the overall population, no differences were observed between the two treatments. Furthermore, symptomatic patients experienced a greater reduction in nighttime symptom severity from baseline to 6 weeks with aclidinium, 
A

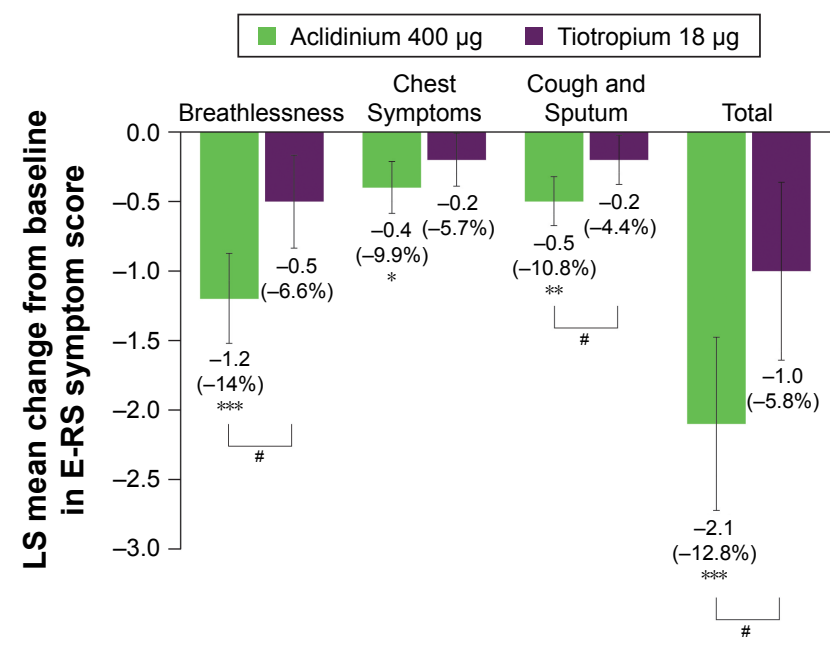

B

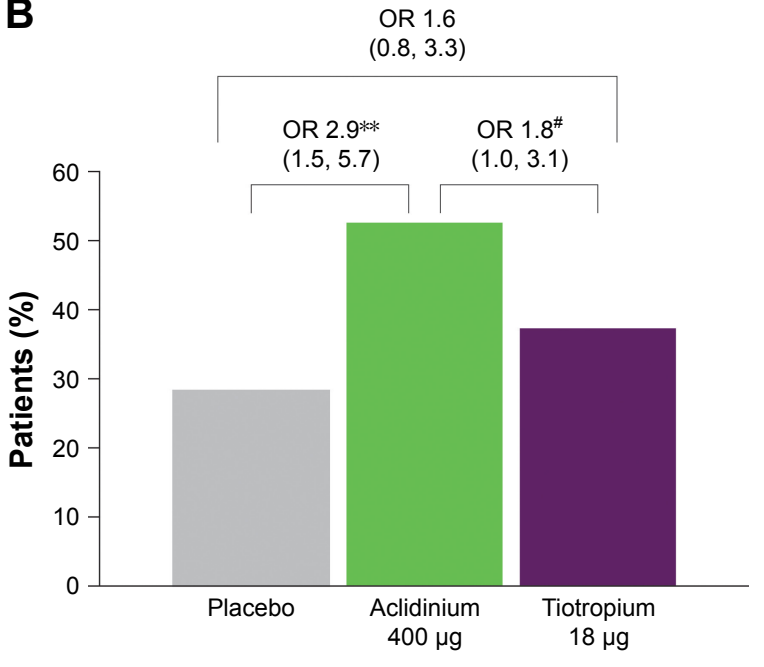

Figure 4 Symptomatic patients: change from baseline in E-RS Total and domain symptom scores versus placebo (A) and percentage of E-RS responders (B) at week 6. Notes: Percentage reduction is shown in brackets. Placebo $\mathrm{N}=60$, aclidinium $400 \mu \mathrm{g} N=1 \mathrm{I}$, tiotropium I8 $\mu \mathrm{g} N=|0|$ I. $* P<0.05$, $* * P<0.0$ I, $* * * P<0.00 \mathrm{I}$ versus placebo; ${ }^{\#} P<0.05$ versus tiotropium. Scores: $0-40$ for Total, 0-17 for Breathlessness, 0-12 for Chest Symptoms, 0-1I for Cough and Sputum.

Abbreviations: E-RS, Evaluating Respiratory Symptoms; LS, least squares; OR, odds ratio.

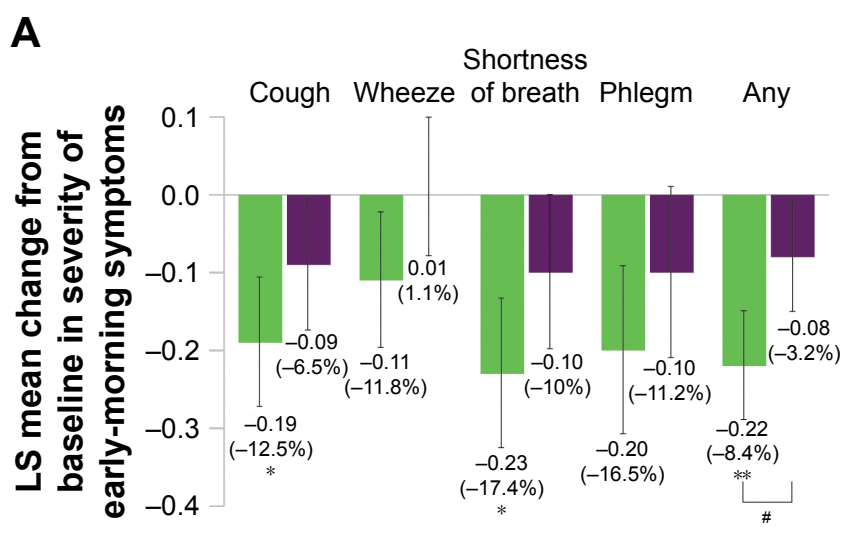

Aclidinium $400 \mu \mathrm{g} \square$ Tiotropium $18 \mu \mathrm{g}$

B

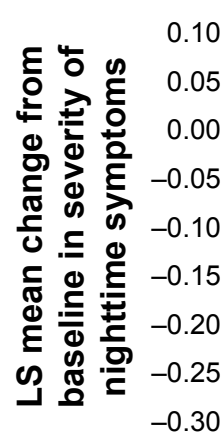

C

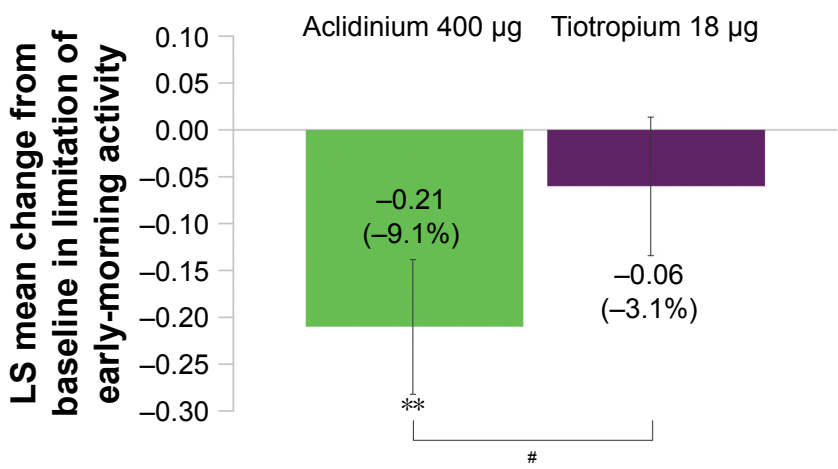

Figure $\mathbf{5}$ Symptomatic patients: change from baseline in symptom severity in the early morning $(\mathbf{A})$ and nighttime (B), and limitation of early-morning activity (C) over 6 weeks.

Notes: Percentage reduction is shown in brackets. Placebo $N=60$, aclidinium $400 \mu \mathrm{g} \mathrm{N}=116$, tiotropium $18 \mu \mathrm{g} N=101$. $* P<0.05$, $* * P<0.01$ versus placebo; ${ }^{*} P<0.05$ versus tiotropium. Specific symptoms (A): I= mild, $2=$ moderate, $3=$ severe, $4=$ very severe; any symptom: I= no symptoms, $2=$ mild, $3=$ moderate, $4=$ severe, $5=$ very severe. For patients with no symptom, a zero value was assigned. Nighttime symptom severity (B): I= mild, $2=$ moderate, $3=$ severe, $4=$ very severe. Limitation of activity (C): I= not at all, $2=$ a little, $3=$ moderately, $4=$ a good deal, $5=$ a very good deal.

Abbreviation: LS, least squares. 
compared with tiotropium. In the overall population, although nighttime symptom severity was significantly reduced with aclidinium versus placebo, the difference between the two comparators was not statistically significant. ${ }^{6}$ For both the overall population and the symptomatic patient group, no differences in nighttime symptom severity were observed for tiotropium versus placebo.

While noting that the BID dosing regimen of aclidinium may have contributed to the observed improvement in nighttime efficacy versus tiotropium QD in symptomatic patients, improvement of nighttime lung function is of particular importance for patients with COPD as nighttime symptoms and poor quality sleep are common. ${ }^{1}$ To date, relatively few studies have demonstrated significant improvements in nighttime lung function and/or sleep quality following bronchodilator therapy. ${ }^{1,18-22}$

The improvements in E-RS score observed in symptomatic patients receiving treatment with aclidinium are likely to be clinically significant since E-RS has been shown to be a valid and reliable tool for the assessment of respiratory symptoms of COPD in clinical trials. ${ }^{11,14,23}$ The minimal clinically important differences for the different aspects of the E-RS tool have recently been proposed: RS-Total $\geq-2$ units; RS-Breathlessness $\geq-1$ unit; RS-Cough and Sputum $\geq-0.7$ units; and RS-Chest Symptoms $\geq-0.7$ units, ${ }^{14}$ and the ability of the E-RS to capture treatment effects has recently been evaluated. ${ }^{11}$ In this study, change in E-RS Total score was -2.8 units with aclidinium versus -0.7 units with placebo and -1.6 units with tiotropium. With aclidinium, changes from baseline in individual domain scores at week 6 were -1.3 for Breathlessness, -0.6 for Chest Symptoms, and -0.8 for Cough and Sputum.

There are some potential limitations of this post hoc analysis. There was found to be a significantly higher proportion of patients with baseline bronchial reversibility in the aclidinium group compared with the tiotropium group, which may potentially account for the significant difference in efficacy observed. The apparent higher proportion of patients with severe COPD in the tiotropium group is, however, unlikely to have influenced the $\mathrm{FEV}_{1}$ response in these patients, since the differences between groups were not found to be significant. Also, the 6-week study period may not be long enough to reflect a patient's symptom burden. In addition, the E-RS threshold used to distinguish symptomatic from asymptomatic patients has not been formally validated and requires further investigation. ${ }^{11}$ One must also consider that unvalidated, early versions of the early-morning (Early Morning Symptoms of COPD Instrument) and nighttime symptoms (Nighttime Symptoms of COPD Instrument) questionnaires were used in this study. Both questionnaires have subsequently been developed and evaluated further, and there are published data indicating that these are valid tools for measuring COPD symptoms in large randomized trials. ${ }^{15,16}$ The use of a patient questionnaire, rather than clinical assessments, to evaluate limitation of early-morning activity could be considered a potential constraint of this study; however, the benefit of this method is that it can assess if patients are restricted in their usual morning activities, such as getting washed and dressed.

One further consideration of this post hoc analysis is that although symptomatic patients constituted $45 \%$ of the overall study population, the total sample size remains relatively small $(n=414)$. Furthermore, it should be noted that it is possible that a different group of symptomatic patients may have been identified if the COPD Assessment Test or modified Medical Research Council criteria outlined in the GOLD report were applied. ${ }^{5}$

\section{Conclusion}

Results from this post hoc analysis of a symptomatic patient group with moderate to severe COPD showed that aclidinium $400 \mu \mathrm{g}$ BID provided additional improvements compared with tiotropium $18 \mu \mathrm{g}$ QD in: 1) bronchodilation, particularly during the nighttime, 2) E-RS responder status, 3) early-morning, daytime, and nighttime symptoms, and 4) early-morning limitation of activity. These results suggest that symptomatic patients may achieve greater benefits during the nighttime with aclidinium treatment than patients with fewer symptoms.

\section{Acknowledgments}

The authors would like to thank all of the patients and their families, the team of investigators, research nurses, and operations staff involved in these studies. This study was funded by Almirall S.A., Barcelona, Spain. The authors would also like to thank Jennifer Higginson of Complete Medical Communications, who provided medical writing support under the direction of the authors, funded by AstraZeneca.

Data included in this paper were presented at the British Thoracic Society Winter Meeting 2015 as a poster discussion session (abstract published in "Poster Abstracts", Thorax 2015;70:A139 [http://thorax.bmj.com/content/70/ Suppl 3/A139; DOI: 10.1136/thoraxjnl-2015-207770.263]), and at the American Thoracic Society International Conference 2016 as a poster presentation (abstract published in "American Thoracic Society International Conference Abstracts", Am J Respir Crit Care Med 2016;193:A6817 [http:/www.atsjournals.org/doi/pdf/10.1164/ 
ajrccm-conference.2016.193.1 MeetingAbstracts.A6817; DOI: 10.1164/ajrccm-conference.2016.193.1_Meeting Abstracts.A6817]).

\section{Disclosure}

JB has received consulting fees, speaker's fees, and travel expenses from AstraZeneca and has also received compensation for organizing or participating in advisory boards for Cytos, Boehringer Ingelheim, Almirall, AstraZeneca, Novartis, and Revotar Biopharmaceuticals. The institution where JB is currently employed has received compensation for the design, performance, or participation in single or multicenter clinical trials in the past 5 years from several companies including Almirall, Altana, AstraZeneca, Boehringer Ingelheim, Cytos, GSK, Meda Pharmaceuticals, Merck Sharp \& Dohme, Mundipharma, Novartis, Pfizer, and Revotar Biopharmaceuticals. RM has received consulting fees, speaker's fees, and travel expenses from Boehringer Ingelheim and has also received compensation for participating in advisory boards for Boehringer Ingelheim, Almirall, AstraZeneca, and Novartis. Furthermore, RM has received compensation for participation in multicenter clinical trials in the past 5 years from several companies including Almirall, AstraZeneca, Boehringer Ingelheim, GSK, Merck Sharp \& Dohme, Mundipharma, Novartis, Pearl, Roche, and Takeda. A-MK is a current employee of Pulmonary Research Institute at LungenClinic Grosshansdorf; the institution received compensation for the design of and/or participation in clinical trials from Almirall, AstraZeneca, Boehringer Ingelheim, GSK, Novartis, Pfizer, Infinity Pharmaceuticals, TEVA, Sterna Biologicals, Chiesi, Bayer, and Takeda. Furthermore, A-MK has received consulting fees, and speaker's fees from AstraZeneca, Boehringer Ingelheim, and Roche. FC and EGG are employees of AstraZeneca PLC, Barcelona, Spain, and former employees of Almirall S.A., Barcelona, Spain.

\section{References}

1. Agusti A, Hedner J, Marin JM, Barbé F, Cazzola M, Rennard S. Nighttime symptoms: a forgotten dimension of COPD. Eur Respir Rev. 2011; 20(121):183-194.

2. Roche N, Chavannes NH, Miravitlles M. COPD symptoms in the morning: impact, evaluation and management. Respir Res. 2013;14:112.

3. Miravitlles M, Worth H, Soler Cataluna JJ, et al. Observational study to characterise 24-hour COPD symptoms and their relationship with patient-reported outcomes: results from the ASSESS study. Respir Res. 2014; $15: 122$.

4. Ehteshami-Afshar S, FitzGerald JM, Doyle-Waters MM, Sadatsafavi M. The global economic burden of asthma and chronic obstructive pulmonary disease. Int J Tuberc Lung Dis. 2016;20:11-23.

5. Global Initiative for Chronic Obstructive Lung Disease. Global strategy for the diagnosis, management, and prevention of chronic obstructive pulmonary disease [updated 2017]. Available from: http://goldcopd.org/ gold-2017-global-strategy-diagnosis-management-prevention-copd/. Accessed November 17, 2016.
6. Beier J, Kirsten AM, Mróz R, et al. Efficacy and safety of aclidinium bromide compared with placebo and tiotropium in patients with moderate-to-severe chronic obstructive pulmonary disease: results from a 6-week, randomized, controlled Phase IIIb study. COPD. 2013;10(4): 511-522.

7. Fuhr R, Magnussen H, Sarem K, et al. Efficacy of aclidinium bromide $400 \mu \mathrm{g}$ twice daily compared with placebo and tiotropium in patients with moderate to severe COPD. Chest. 2012;141(3):745-752.

8. Marth K, Schuller E, Pohl W. Improvements in patient-reported outcomes: a prospective, non-interventional study with aclidinium bromide for treatment of COPD. Respir Med. 2015;109(5): 616-624.

9. Beier J, Kirsten A-M, Mroz R, et al. Efficacy of aclidinium bromide compared with tiotropium and placebo in patients with moderate to severe COPD: a phase IIIb study. Thorax. 2012;67:A26-A27.

10. Fuhr R, Magnussen H, Ribera Llovera A, et al. Efficacy and safety of twice-daily aclidinium bromide compared with tiotropium and placebo in patients with moderate to severe COPD. Eur Respir J. 2010; 36(Suppl 54):219s.

11. Jones PW, Leidy NK, Hareendran A, Lamarca R, Chuecos F, Garcia Gil E. The effect of aclidinium bromide on daily respiratory symptoms of COPD, measured using the Evaluating Respiratory Symptoms in COPD (E-RS: COPD) diary: pooled analysis of two 6-month Phase III studies. Respir Res. 2016;17(1):61.

12. Leidy NK, Murray LT, Jones P, Sethi S. Performance of the EXAcerbations of chronic pulmonary disease tool patient-reported outcome measure in three clinical trials of chronic obstructive pulmonary disease. Ann Am Thorac Soc. 2014;11:316-325.

13. Leidy NK, Sexton CC, Jones PW, et al. Measuring respiratory symptoms in clinical trials of COPD: reliability and validity of a daily diary. Thorax. 2014;69(5):443-449.

14. Leidy NK, Murray LT, Monz BU, et al. Measuring respiratory symptoms of COPD: performance of the EXACT-Respiratory Symptoms Tool (E-RS) in three clinical trials. Respir Res. 2014; 15(1): 124

15. Mocarski M, Zaiser E, Trundell D, Make BJ, Hareendran A. Evaluation of the psychometric properties of the nighttime symptoms of COPD instrument. Int J Chron Obstruct Pulmon Dis. 2015;10:475-487.

16. Hareendran A, Zaiser E, Make B, Garcia-Gil E. The development and psychometric validation of the early morning symptoms of COPD instrument (EMSCI). Thorax. 2016;71(Suppl 3):A204, P218 (abstract).

17. Qaseem A, Wilt TJ, Weinberger SE, et al. Diagnosis and management of stable chronic obstructive pulmonary disease: a clinical practice guideline update from the American College of Physicians, American College of Chest Physicians, American Thoracic Society, and European Respiratory Society. Ann Intern Med. 2011;155(3):179-191.

18. Calverley PM, Lee A, Towse L, van Noord J, Witek TJ, Kelsen S. Effect of tiotropium bromide on circadian variation in airflow limitation in chronic obstructive pulmonary disease. Thorax. 2003;58(10): $855-860$.

19. Martin RJ, Bartelson BL, Smith P, et al. Effect of ipratropium bromide treatment on oxygen saturation and sleep quality in COPD. Chest. 1999; 115(5):1338-1345.

20. McNicholas WT, Calverley PM, Lee A, Edwards JC. Long-acting inhaled anticholinergic therapy improves sleeping oxygen saturation in COPD. Eur Respir J. 2004;23(6):825-831.

21. Mulloy E, McNicholas WT. Theophylline improves gas exchange during rest, exercise, and sleep in severe chronic obstructive pulmonary disease. Am Rev Respir Dis. 1993;148(4 Pt 1):1030-1036.

22. Ryan S, Doherty LS, Rock C, Nolan GM, McNicholas WT. Effects of salmeterol on sleeping oxygen saturation in chronic obstructive pulmonary disease. Respiration. 2010;79(6):475-481.

23. Leidy NK, Kimel M, Ajagbe L, Kim K, Hamilton A, Becker K. Designing trials of behavioral interventions to increase physical activity in patients with COPD: insights from the chronic disease literature. Respir Med. 2014;108(3):472-481. 


\section{Publish your work in this journal}

The International Journal of COPD is an international, peer-reviewed journal of therapeutics and pharmacology focusing on concise rapid reporting of clinical studies and reviews in COPD. Special focus is given to the pathophysiological processes underlying the disease, intervention programs, patient focused education, and self management protocols.

This journal is indexed on PubMed Central, MedLine and CAS. The manuscript management system is completely online and includes a very quick and fair peer-review system, which is all easy to use. Visit http://www.dovepress.com/testimonials.php to read real quotes from published authors. 